\title{
A case report of paroxysmal dystonic choreoathetosis due to hypoglycaemia induced by an insulinoma
}

\author{
Christopher Shaw, Lindsay Haas, David Miller, John Delahunt
}

\begin{abstract}
Hypoglycaemia due to an insulinoma can mimic acute disorders of cognition, consciousness, epilepsy, transient ischaemia, or psychosis, and chronic disorders of dementia and neuropathy. Misdiagnosis and delay in treatment are common and prolonged hypoglycaemia can lead to permanent neurological deficit or fatal coma. A 27 year old woman with hypoglycaemia induced by an insulinoma presented with features typical of paroxysmal nonkinesiogenic dystonic choreoathetosis. Striatal dysfunction as a consequence of hypoglycaemia has rarely been described. Insulinoma is a readily treatable condition that should be considered in the differential diagnosis of a paroxysmal movement disorder.
\end{abstract}

(F Neurol Neurosurg Psychiatry 1996;61:194-195)

Keywords: paroxysmal dystomic choreoathetosis; hypoglycaemia; insulinoma

Paroxysmal non-kinesiogenic dystonic choreoathetosis (PDC) describes attacks of dystonic posture, chorea, athetosis, or ballism in any combination. Typically the episodes last between five minutes and four hours, being longer in duration but less frequent than paroxysmal kinesiogenic choreoathetosis (PKC). They are not precipitated by sudden movement or startle and do not respond to anticonvulsants. Speech may be affected by dystonia and patients often report abnormal sensations in their limbs at the start of an attack. Most reported cases of PDC are idiopathic or familial in aetiology and when associated with exercise are considered to be an intermediate form of PDC. ${ }^{1}$ Our patient presented with features of exercise associated PDC due to hypoglycaemia caused by an insulinoma.

\section{Case report}

A 27 year old woman developed episodes of exercise associated postural disturbance and involuntary movement over a period of four months. The first episode occurred after a morning aerobics session, when she found her- self bumping into people and involuntarily backing away when she wanted to stand still and talk. A fortnight later when she was walking home from work she felt that her right shoe did not fit properly and that she did not know where it was when she put it down. On arriving home she noticed a brief episode of horizontal diplopia and poor balance with difficulty maintaining her posture while putting her right leg into her trousers. This episode lasted 30 minutes and resolved completely after eating food. Another episode occurred while driving when she lost control over the accelerator pedal causing her to accelerate involuntarily. The most dramatic episode occurred while attending a conference. She had omitted breakfast and was taking a walk after a long lecture when she felt tightness in both calves and her shoes felt as if they did not fit properly. Her right foot cramped into a flexed and inverted posture. She sat down in a café and noticed clumsiness in placing her cup in its saucer and her speech became slow. She walked back to the conference but had difficulty controlling her right leg. As she seated herself, her legs felt restless. Witnesses described rocking movements of her trunk with irregular jerking and writhing movements of her limbs and torso with frequent arching of her back. She was assisted from the room and the movements settled slowly, lasting $30 \mathrm{~min}$ utes in total. Afterwards she felt nauseated and resisted efforts to take her to hospital in an ambulance. Her serum glucose was recorded at $3.2 \mathrm{mmol} / \mathrm{l}$ on arrival and on eating food she completely recovered apart from a diffuse headache. Apart from a grade II systolic murmur her general physical and neurological examinations were normal. Blood tests including random glucose blood film, erythrocyte sedimentation rate, thyroid function, copper, and caeruloplasmin were all normal. Her autoantibody screen detected a weakly positive antinuclear antibody at 1:20 in a speckled diffuse pattern. Her EEG was normal. Head CT disclosed abnormal enhancement at the left cerebellopontine angle but vertebral angiography showed this to be a tortuous basilar artery. The working diagnosis was of vertebrobasilar migraine until she developed a further attack of choreoathetoid movements and dystonic posturing of her limbs and trunk during an afternoon outpatient clinic. Blood samples 
Results of prolonged fast demonstrating spontaneous hypoglycaemia

\begin{tabular}{lcccccc}
\hline Time $(h)$ & 0800 & 1020 & 1230 & 1300 & 1330 & 1440 \\
\hline Blood sugar (mmol) & $2 \cdot 4$ & $1 \cdot 7$ & $1 \cdot 5$ & $1 \cdot 6$ & $1 \cdot 6$ & $2 \cdot 1$ \\
Insulin (pmol) & 25 & 39 & 42 & 44 & 39 & 48 \\
C peptide (pmol) & 246 & 341 & 381 & 430 & 432 & 465
\end{tabular}

After 29 hours blood sugar fell to $<2.5 \mathrm{mmol}$ with high concentrations of insulin (fasting range 5-75 pmol, and in the presence of hypoglycaemia $<5$ pmol) and $\mathrm{C}$ peptide (fasting range $250-1100 \mathrm{pmol}$, and in the presence of hypoglycaemia $<200 \mathrm{pM}$ ) suggesting inappropriate endogenous insulin secretion.

taken shortly after this had a glucose concentration of $1.7 \mathrm{mmol} / 1$ (normal $>2.5 \mathrm{mmol} / \mathrm{l}$ ) and her symptoms resolved on eating. An insulin challenge test showed inappropriately raised concentrations of $C$ peptide, confirming endogenous insulin secretion. Twenty nine hours of fasting test provoked spontaneous hypoglycaemia with a blood sugar of $1.5 \mathrm{mmol}$ and inappropriately high insulin and $C$ peptide concentrations (table). Proinsulin was $30 \%$ of the detectable insulin (normal $<5 \%$ ), supporting the diagnosis of insulinoma and suggesting a benign tumour (carcinoma often $>60 \%$ ). Abdominal CT was normal but coeliac axis angiography suggested a small tumour in the tail of the pancreas. At operation a $2 \mathrm{~cm}$ tumour was resected and histology showed nests of islet cells. Immunohistochemical staining and electron microscopy confirmed the presence of insulin. Postoperatively the patient reported a significant improvement in her intellectual performance and there was no recurrence of her symptoms during a five year follow up.

\section{Discussion}

Paroxysmal movement disorders have been symptomatic of hypoglycaemia in only two contemporary case reports. Newman and Kinkel reported a diabetic woman who developed two episodes of limb choreoathetosis and opisthotonus associated with hypoglycaemia after a morphine injection for severe headache and vomiting. ${ }^{2}$ Winer et al described a woman with an insulinoma who, when recovering from hypoglycaemic attacks, adopted tonic flexion of her arms, extension of her legs and laterocollis, and flexion of the trunk. ${ }^{3}$ Historical reports of insulin shock therapy describe transient choreoathetosis in some patients ${ }^{4}$ but more commonly the disorder was permanent. ${ }^{5}$

Many patients with an insulinoma do not report the adrenergic symptoms of hypoglycaemia and present with neurological or psychiatric manifestations that often lead to misdiagnosis. ${ }^{6-7}$ In Daggett and Nabarro's review of 252 reported cases the most common neurological symptoms were confusion, coma, and seizures. Non-specific headache, generalised weakness, paraesthesia, and stroke-like paralysis were less frequent and dizziness and dysarthria were uncommon. ${ }^{8}$ Chronic neuropathic and dementing syndromes due to hypoglycaemia have also been described. ${ }^{910}$ In a prospective survey, two of 25 patients referred to neurologists with "funny turns" were found to have an insulinoma. ${ }^{11}$

Huntingdon's disease is associated with striatal degeneration and hypometabolism on ${ }^{18} \mathrm{~F}$-fluorodeoxyglucose and PET imaging, ${ }^{12}$ whereas the reversible choreas such as Sydenham's chorea, systemic lupus erythematosus, and antiphospholipid syndrome show striatal hypermetabolism. ${ }^{13-15}$ The precise pathophysiology of chorea in these conditions has not been established but we postulate that in our patient hypoglycaemia led to temporary striatal dysfunction. This in turn may have led to defective pallidal and subthalamic inhibitory outflow to the thalamus, with overactivity of thalamocortical excitatory projections resulting in hyperkinesia. In the absence of a recognised predisposing factor for chorea we postulate that the striatal response to hypoglycaemia must vary between subjects.

Hypoglycaemia due to insulinoma is uncommon and difficult to diagnose as it mimics a great variety of neurological conditions. It may have grave consequences but is often curable and must be considered in the differential diagnosis of a paroxysmal movement disorder.

1 Fahn SH. The paroxysmal dyskinesias. In: Marsden CD, Fahn SH, eds. Movement disorders 3. Oxford: Butterworth Fahn SH, eds. Movement disor

Heinemann, 1994:310-45.
2 Newman R, Kinkel W. Paroxysmal choreoathetosis due to hypoglycaemia. Arch Neurol 1984;41:341-2.

3 Winer J, Fish D, Sawyers D, Marsden CD. A movement disorder as a presenting feature of recurrent hypoglycaemia. Mov Disord 1990;5:176-7.

4 Golden L. Neurologic manifestations in "hypoglycaemic shock". Ann Intern Med 1937;11:819-22.

5 Richardson J, Chambers R, Heywood P. Encephalopathies of anoxia and hypoglycaemia. Arch Neurol 1959;1:178-9.

6 Best J, Chisholm D, Alford F. Insulinoma: poor recognition of clinical features is the major problem in diagnosis. Med $\mathcal{F}$ A ust 1978;2:1-5.

7 Service F, Dale A, Elveback L, Jiang N-S. Insulinoma, clinical and diagnostic features of 60 consecutive cases. Mayo Clin Proc 1976;51:417-29.

8 Daggett $P$, Nabarro J. Neurological aspects of insulinomas. Postgrad Med F 1984;60:577-81.

9 Danta G. Hypoglycaemic peripheral neuropathy. Arch Neurol 1969;21:121-32.

10 Snook JA, vander Star R, Weller RO. Insulinoma producing progressive neurological deterioration over 30 years BrMed $\mathcal{1}$ 1986;293:241-2.

11 Harrington MG, McGeorge AP, Balantyne JP. A prospective survey for insulinomas in a neurology department. Lancet 1983;i:1094-5.

12 Grafton S, Mazziotta J, Pahl J, et al. Serial changes of cerebral glucose metabolism and caudate size in persons at risk for Huntington's disease. Arch Neurol 1992;49: 1161-7.

13 Goldman S, Amrom D, Szliwowski H, et al. Reversible striatal hypermetabolism in a case of Sydenham's chorea. Mov Disord 1993;8:355-8.

14 Guttman M, Lang A, Garnett E, et al. Regional cerebral glucose metabolism in SLE chorea: further evidence that striatal hypometabolism is not a correlate of chorea. Mov Disord 1987;2:201-10.

15 Furie R, Ishikawa T, Dhawan V, Eidelberg D. Alternating hemichorea in primary antiphospholipid syndrome: evidence for contralateral striatal hypermetabolism. Neurology 1994;44:2197-9. 